\title{
Platform Launch Strategies
}

\author{
Christian Stummer • Dennis Kundisch • \\ Reinhold Decker
}

Received: 1 June 2017/Accepted: 27 November 2017/Published online: 22 January 2018

(C) Springer Fachmedien Wiesbaden GmbH, part of Springer Nature 2018

Keywords Multi-sided platform · Two-sided market . Launch strategy · Network effect · Chicken-and-egg dilemma $\cdot$ Mutual baiting problem

\section{Multi-sided Platforms and the Chicken-and-Egg Dilemma}

Today, digital platforms mediating between independent groups of users account for a total market value of about US- $\$ 4.3$ trillion and an employment base of several million direct and indirect employees (Evans and Gawer 2016). A multi-sided platform (MSP) - in the literature also referred to as two-sided platform, two-sided market, or multi-sided market - constitutes a market that enables interaction between at least two sets of users through an intermediary,

Accepted after one revision by Prof. Dr. Weinhardt.

Prof. Dr. C. Stummer

Fakultät für Wirtschaftswissenschaften, Lehrstuhl für

Betriebswirtschaftslehre, insb. Innovations- und

Technologiemanagement, Universität Bielefeld,

Universitätsstraße 25, 33615 Bielefeld, Germany

e-mail: christian.stummer@uni-bielefeld.de

Prof. Dr. D. Kundisch ( $\square)$

Lehrstuhl für Wirtschaftsinformatik, insb. Digitale Märkte, Department Wirtschaftsinformatik, Fakultät für

Wirtschaftswissenschaften, Universität Paderborn, Warburger

Straße 100, 33098 Paderborn, Germany

e-mail: dennis.kundisch@wiwi.uni-paderborn.de

Prof. Dr. R. Decker

Fakultät für Wirtschaftswissenschaften, Lehrstuhl für Betriebswirtschaftslehre, insb. Marketing, Universität Bielefeld, Universitätsstraße 25, 33615 Bielefeld, Germany

e-mail: rdecker@uni-bielefeld.de where the decisions of each group of users on either side of the market affects the outcomes of the users on the other side(s) (Rochet and Tirole 2004; Rysman 2009; Hagiu and Wright 2015). MSPs have impressively demonstrated their disruptive potential in well-established global industries. Airbnb, for instance, leads the CNBC disruptor 50 list (CNBC 2017) and, with a market valuation of US\$31 billion, comes second after the Marriott group in the lodging industry (Bensinger 2017). Its two-sided platform mediates between traveling people who seek accommodation and hosts willing to share their accommodation. The exponential growth of its platform started around 2011, when the critical inflection point (in respect of the number of users) was reached and network effects started to kick in (Hagiu and Rothman 2016). As the first in its industry, Airbnb has been able to solve one of the critical early-stage challenges of MSPs, namely the mutual baiting problem, which often is referred to as the 'chicken-and-egg dilemma' of multi-sided digital platforms.

MSPs have been a popular research topic for scholars in the fields of economics, strategic management, and, more recently, as a consequence of the emergence of large-scale web-based platforms, to information systems scholars. Two major streams of research on MSPs can be distinguished. The first stream examines pricing and commission choices (Armstrong 2006; Chao and Derdenger 2013; Dou et al. 2016; Eisenmann et al. 2006; Parker and Van Alstyne 2005; Rochet and Tirole 2003, 2006; Rysman 2009), while the second stream investigates choices with regard to platform design and investments, such as the quality of technology and rules of interaction (Bakos and Katsamakas 2008), the effects of advertisement (Tucker and Zhang 2010) and ownership model (Yoo et al. 2002), business model design (Hagiu and Wright 2015), value-added services (Anderson et al. 2014), competition among platforms 
(Caillaud and Jullien 2003), platform openness (Rysman 2009), and revenue optimization (Voigt and Hinz 2015).

In most of the above works, economic theories of network externalities (Katz and Shapiro 1985; Liebowitz and Margolis 1994; Rochet and Tirole 2004) play a significant role. On MSPs, network effects can emerge on one side of the platform (i.e., same-side network effects) and across sides (i.e., cross-side network effects; see Voigt and Hinz 2015). The latter give rise to the chicken-and-egg dilemma of early-stage MSPs. This dilemma describes the need for a critical number of sellers (or volume of supply) to attract buyers (or demand); however, sellers will only adopt the platform and invest if they expect a sufficient number of buyers on the other side to join (Armstrong 2006; Caillaud and Jullien 2003; Eisenmann et al. 2006). Once MSPs reach the critical user mass on each side of the platform, the effects of network externalities turn positive and stimulate platform growth (Hagiu and Rothman 2016). The utilization of positive network externalities beyond the critical inflection point has been a popular research topic. We refer to Chu and Manchanda (2016) for a state-of-theart overview of the relevance of cross-side network effects on the evolution of large-scale online consumer-to-consumer platforms.

Although research on cross-side network effects has been dominated by formal economic models, some empirical studies have also elaborated on the presence and magnitude of cross-side network effects. General empirical evidence for the existence of significant cross-side network effects has been verified, for instance, in the market for yellow pages (Rysman 2004), in the television-advertising industry (Wilbur 2008), and in the personal computer industry (Stremersch et al. 2007). Ackerberg and Gowrisankaran (2006) estimated the size and importance of cross-side network effects in the banking industry and found that in the case of high adoption costs for potential users, MSPs need to offer appropriate incentives to ensure that they reach the critical user mass. Moreover, Chu and Manchanda (2016) quantified cross-side network effects and concluded that they are asymmetrical, as the growth of buyers (platform demand) benefits more from a large base of sellers (platform supply) than vice versa.

In the following, typical platform launch strategies also referred to as platform seeding strategies, platform scaling, platform scaling-up strategies - able to tackle the underlying chicken-and-egg dilemma for early-stage MSPs are presented. While it might be possible for some platforms to apply any of these launch strategies or to even combine several strategies, this will not be the case for all platforms.

\section{Platform Launch Strategies for Solving the Chicken- and-Egg Dilemma}

The following discussion of launch strategies for solving the chicken-and-egg dilemma builds on academic literature in economics, management and information systems, as well as practitioner-oriented publications on the web that primarily address the high-tech startup community. We aggregate and structure the identified strategic patterns into six distinct strategies, namely focusing on (1) a single target group, (2) platform staging, (3) subsidizing, (4) platform envelopment, (5) exclusivity agreements, and (6) side switching. These strategies specifically address the chicken-and-egg dilemma of early-stage MSPs and may be applied individually or in combination.

To illustrate the application of these strategies, we refer to examples from the crowdworking industry. Crowdworking, also referred to as microworking, is a form of online outsourcing with several hundreds of active mediating workplace platforms. Kuek et al. (2015) defined it as an approach to breaking down projects and tasks into microtasks that can be completed in seconds or in a few minutes. Microtasks, such as image tagging, text transcription, or data entry, usually require basic numeracy and literacy skills. Microworkers are typically paid small amounts of money for completing microtasks. The crowdworking industry constitutes a particularly interesting field of application for the strategies discussed in our paper. On the one hand, this industry shows relatively consolidated structures for web-based platforms, with Amazon's Mechanical Turk (MTurk) and CrowdFlower representing about $80 \%$ of the global web market (Kuek et al. 2015). On the other hand, however, new crowdworking industry segments are currently emerging enabled by technological innovations such as mobile crowdworking via smartphones, or crowdworking via augmented reality and virtual reality. Correspondingly, a wide range of startups and established businesses have entered these emerging industry segments with platform concepts that may stimulate research and the overall understanding of MSPs.

\subsection{Single Target Group}

Focusing on one particular target group or market segment is a well-known strategy (cf., e.g., Porter 1980). To this end, MSPs may start, for example, with a single city or industry. By reducing the total market size and the required critical user mass, MSPs require fewer resources and less time to reach the critical inflection point from which the MSP can grow to other market segments. When initially focusing on a single market segment, MSPs can achieve higher levels of differentiation and platform performance 
in this market segment, which increases expectations among potential platform users that everyone else will adopt the same platform in future (Cennamo and Santalo 2013). Uber initially limited its operations to San Francisco and once it was successful in this city, the management decided to expand its business to other locations.

There are at least two variations of this strategy.

- Marquee users: An MSP focusing on marquee users initially acquires users whose participation brings extraordinary value for other platform users, thereby potentially attracting a higher number of new users (Eisenmann et al. 2006; Rochet and Tirole 2003). Among other attributes, marquee users can be opinion leaders, bring high-quality transactions to the MSP (Binken and Stremersch 2009; Landsman and Stremersch 2011), or serve as very active users (Wilson et al. 2009).

- Loyal users: The second variation of this strategy results from focusing on loyal users. These may be captive on a platform for various reasons, such as lower price sensitivity (Rochet and Tirole 2003), higher sunk costs (Evans 2003), or positive expectations for platform development (Zhu and Iansiti 2012). Loyal users tend to display a lower willingness to churn (i.e. discontinue platform usage) and thus allow MSPs to reach the required user mass with lower financial resources. Moreover, a substantial share of loyal users often involve a lower price elasticity, thus providing more opportunities for the MSP to capitalize on transactions (Rysman 2009).

In the crowdworking industry, marquee users can be suppliers of attractive or well-paid tasks on the supply side, in turn attracting many workers on the demand side. The execution of a loyal user strategy, in contrast, may include designing an MSP that is primarily or solely used through an application programming interface (API), as this causes higher adoption costs (i.e. sunk costs) in the form of programming and adjustment of business processes compared to adoption via a standardized web interface. Over time, once a company continues to adjust its business processes toward the platform, switching costs may increase as a result. Another measure available to crowdworking platforms is to set up a reputation regime for the amount and quality of work or tasks provided, which is particularly valuable for receiving tasks or finding good workers (Fiverr and MTurk may serve as examples). Such a regime seeks to retain loyal users by increasing switching costs to another platform, since a user would lose her profile history and has to rebuild her reputation from scratch. A third method for increasing social binding and commitment to a platform would be to adopt a by-invitation-only platform.

\subsection{Platform Staging}

With the platform-staging strategy, an MSP evolves in two distinct steps from a traditional vendor-based business model in the first stage to a platform mediation business model in the second stage after reaching the critical user mass (Hagiu and Eisenmann 2007; Hagiu and Wright 2015). This strategy can help MSPs to focus on one market side at a time, thereby avoiding negative indirect network effects in the early development stage. Amazon, for instance, initially launched its crowdworking platform MTurk as a service for its own purposes (Menezes 2013). By providing the supply side completely independently (first-party content), Amazon had the opportunity to focus on building the demand side of workers (Hagiu and Spulber 2013). In a second stage, after reaching a considerable worker base, Amazon started to open its platform to other companies with similar needs and evolved MTurk to a platform mediating between two groups of users. This strategy can also be applied by MSPs without an independent source of supply by contracting third-party suppliers with a traditional vendor business model in the first stage. A variation of the staging strategy aims at starting as a single-sided platform. The OpenTable restaurant reservation service, for example, distributed booking management systems in the first stage, which restaurants then used as a standalone application to manage table bookings. Once they had enough restaurants on board, and hence access to their seating inventory, they opened the demand side and collected a commission from the restaurants for every referred customer. When executing a staging strategy, the platform design should be geared toward the final MSP architecture from the outset (Eisenmann et al. 2008), although a traditional business model may be applied in the first stage.

Platform-staging strategies are of particular interest for the supply side of crowdworking platforms. In this regard, Amazon constitutes a rather rare example of being able to provide sufficient first-party content independently to reach the critical mass of workers before starting to evolve into an MSP. Alternatively, early-stage crowdworking platforms have the opportunity to act as vendors of microtask services initially, thereby reducing the otherwise negative cross-side network effects of a low initial worker base. Another strategic opportunity for young crowdworking platforms worth investigating is starting as an application with standalone functionalities. Following the example of OpenTable, a crowdworking platform may offer a standalone application to break down complex business workflows into small tasks that can more easily be outsourced to third parties. In the second stage, the crowdworking platform then gradually acquires users of the standalone application as platform users on the supply side. 
As a strategic advantage, users of the standalone applications have reduced adoption costs when business processes have already been managed in small tasks with a compatible application.

\subsection{Subsidizing}

Subsidizing strategies play a prominent role in platformmediated business models; thus, they have been studied extensively in the economic literature (Anderson et al. 2014; Rochet and Tirole 2006). Due to cross-side network effects, subsidizing decisions on one side also affect adoption on the other side (Armstrong 2006). Such MSPs typically have a 'subsidy side' that allows the use of the platform with discounts or even for free, and a 'money side' that is charged for participation or transactions (Eisenmann et al. 2006). Subsidizing one side of the market to attract the 'money side' of the MSP until the critical inflection point is reached is a common strategy (Eisenmann et al. 2011; Fath and Sarvary 2003). This can take different forms, such as price cuts, free usage, offers of investment incentives (Ackerberg and Gowrisankaran 2006; Hagiu 2009; Muzellec et al. 2015), offers of valueadded services (Dou et al. 2016), technical support for development programming (Schilling 2003), and even paying users as a means of attracting them (Evans 2003). An MSP can therefore afford to sustain a loss on the 'subsidy side' as long as the loss is recovered on the 'money side' (Armstrong and Wright 2007). The decision as to which side to charge and how (calculation and charging mechanism) is complex and depends on factors like the users' sensitivity to price (Hagiu and Spulber 2013) or quality (Eisenmann et al. 2006). In the context of video game systems in the United States, Clements and Ohashi (2005) found empirical evidence to support the view that initial subsidizing is an effective practice.

In the crowdworking industry, workers represent the 'subsidy side' and usually they have fully subsidized access to the platform. On the 'money side', businesses are charged via various pricing and commission mechanisms. In this respect, most subsidizing strategies on MSPs show some pattern of market penetration strategy with a low starting price, and increase their price once a user base has been established (Cennamo and Santalo 2013; Rysman 2009).

\subsection{Platform Envelopment}

The platform envelopment strategy aims at leveraging the shared relationships with (other) established platforms and their networks (Eisenmann et al. 2006). When applying such a strategy, an MSP strives to combine its own functionalities with those of a target platform in a multi- platform bundle that leverages shared user relationships (Eisenmann et al. 2011). This is possible because many industries with MSPs are neither exclusive nor do they operate in a 'winner takes all' market setting (Caillaud and Jullien 2003) which allows multiple MSPs to coexist (Shankar and Bayus 2003). Rather than building a platform from scratch, the platform envelopment strategy aims at partnering with existing and potentially large platforms with a view to growing with them (Rochet and Tirole 2003).

In addition to a substantial overlap in the user base, the platform envelopment strategy also requires low costs for switching or multihoming users (Armstrong 2006). Multihoming refers to the simultaneous usage of multiple platforms for a similar purpose, such as gaming - when a user owns multiple gaming consoles to play a wider range of computer games - or crowdworking (Landsman and Stremersch 2011) whereby a user may be affiliated with more than one crowdworking platform to receive access to a larger pool of tasks. The corresponding multihoming costs comprise all expenses users incur, including adoption, operation and opportunity costs (Eisenmann et al. 2006). Many MSPs face multihoming on one or both sides (Armstrong and Wright 2007; Evans 2003).

Another approach to executing the platform envelopment strategy is automated harvesting, that is, the collection and processing of information already stored elsewhere. MSPs can apply automated harvesting techniques to seed (usually) one side of the market (Sokoler 2011). Content providers like Amazon, Google, CNET, Facebook, and Twitter offer APIs that MSPs can use to first acquire content and users for one side of the platform and then seek to attract users on the other side. This may still apply in the absence of an API or direct-feed opportunities as MSPs can use some popular techniques, such as web scraping, to acquire both content and users.

In the crowdworking industry, multihoming is common on the demand side. Microworkers tend to use multiple platforms to enlarge their access to the limited number of paid microtasks (Kuek et al. 2015). Due to low multihoming costs for microworkers, platform envelopment is a viable strategy for the demand side of early-stage crowdworking platforms. As an example, CrowdFlower applied an envelopment strategy in its early development stage on the demand side through publishing tasks on the much larger MTurk microworker network. On the supply side, multihoming is less frequent because of the costs incurred by businesses to adopt an additional crowdworking platform, especially in respect of integrating multiple platforms in business processes and programming multiple interfaces. 


\subsection{Exclusivity Agreements}

Signing exclusivity agreements on one market side can attract other users on both market sides (Cennamo and Santalo 2013). In the gaming industry, for example, MSP providers like Sony and Microsoft mediate between game developers and game consumers. Both contracted Electronic Arts, the dominant sports game manufacturer at that time, in order to achieve some form of (temporary) exclusivity for some games that are supposed to attract both gamers and other game developers to their consoles (Eisenmann et al. 2006; Rysman 2009; Parker et al. 2016). Exclusivity agreements have been proven to enhance the competitiveness of an MSP's offering (Armstrong and Wright 2007; Hagiu 2009). Moreover, exclusivity agreements with marquee users potentially increase the overall quality of content on an MSP, as they diminish the adverse selection problem of attracting lower quality content (Cennamo and Santalo 2013). Especially for early-stage MSPs, exclusive affiliations with marquee users and exclusive rights to high-quality content can help signaling positive prospects for the platform and accelerate a platform's growth (Eisenmann et al. 2008).

Signing exclusivity agreements with marquee users for the sake of attracting other users to the early-stage platform is a less frequently applied strategy in the crowdworking industry. However, some crowdworking platforms, such as Fiverr, use such exclusivity agreements with all microworkers. Correspondingly, all advertisements of services provided by microworkers must be labeled with 'Exclusively on Fiverr'.

\subsection{Side Switching}

The idea behind the side-switching strategy is to make a two-sided platform one-sided by finding a platform design that allows users to fill both market sides of the MSP at the same time. Obviously, this strategy only works if services or products of both sides do not require high set-up costs or specific knowledge. The concept of side switching on MSPs has already been addressed by Gazé and Vaubourg (2011), but to the best of our knowledge, it has not yet been considered in terms of its application in platform launch strategies for solving the chicken-and-egg problem. Etsy and Airbnb are among the most popular examples of companies that have successfully applied this strategy in early-stage platform development. As people who are likely to buy handmade goods are also likely to sell them, Etsy focused on this target group to fill both sides of its MSP simultaneously before expanding to other target groups that fill only one side of the market. Similarly, Airbnb targeted private users who could both offer and demand accommodation for travel purposes. Such a strategy would not have worked if Airbnb had only targeted a business-to-business (B2B) accommodation audience that would primarily provide supply to the platform, as a successful execution of this strategy requires MSPs to build a user base that benefits from side switching (Gazé and Vaubourg 2011). Moreover, a single-city user base for the early-stage Airbnb platform would likely have been less attractive for users, as they typically do not seek to rent accommodation in the same city where they live. In contrast, a user base distributed over two cities with substantial travel volume between them would be able to exploit sideswitching effects.

Side switching as a strategy may also be a viable option for a crowdworking platform when focusing on use cases that users can approach from both sides. Market research for startups may be a suitable crowdworking use case for which startup founders provide platform supply in the form of market research tasks while potentially belonging to the target group of market research studies from other startups on the same platform. Another potential use case for a sideswitching strategy may be empirical research with a user base of students that both conduct and participate in research studies. The German market research startup Appinio applies the side-switching strategy on their platform by encouraging participants in market research studies to carry out their own research on its platform using the compensation they earned from completing other users' questionnaires. The established crowdworking platforms Fiverr and MTurk may serve as further examples as in both cases contributors (i.e. workers) also may take over the role of requesters (i.e. buyers).

\section{Conclusion and Outlook}

Cross-side network effects on MSPs have been a popular topic in the literature for some time. Corresponding research has provided valuable insights into the nature and key principles of markets that mediate products or services between two or more groups of users. The practical relevance of such work has become even greater with the emergence of digital MSPs, which have impressively demonstrated their potential to disrupt major industries on a global scale within a few years. It is safe to assume that the impact of platform businesses will increase in information-intensive industries, industries with non-scalable gatekeepers, highly fragmented industries as well as industries with extreme information asymmetries, which notably include education, health care, energy, finance, logistics and transportation and, last but not least, labor and professional services (Parker et al. 2016).

In all of the above sectors and probably several others as well, we will see new MSPs struggling to solve the 
chicken-and-egg dilemma. The management of these MSPs may apply one or a combination of the six generic platform launch strategies that have been outlined above.

The apparent lack of empirical evidence on the effectiveness of these strategies and, particularly so, on the effectiveness of combinations of these strategies, offers a promising direction for further research aimed at advancing our understanding of why many early-stage MSPs fail and others succeed. Future research in this direction should also strive to identify universally valid success factors of MSP activities. Given that mediating platforms may also contain more than two sides, and that they can coexist with a traditional one-sided merchant business model in an overarching selling strategy (Rysman 2009), the investigation of these different types of platforms and the underlying business models, respectively, constitutes a second field for further research (see, e.g., Veit et al. 2014, for a general research agenda on business models). Further, it could be worthwhile to employ novel research methods. So far, most insights are derived from case studies of successful or failed platforms. As the number of these platforms is still relatively small and the characteristics of the market they have been situated in is quite diverse, cumulative learning is limited. Quantitative modeling and simulating the establishment of a platform that employs some launching strategy (or a combination of several launching strategies) therefore seems to be a particularly promising approach (for an overview of such market simulations from innovation diffusion research see Kiesling et al. 2012). As a useful by-product, the aforesaid modeling and simulation approaches might contribute to "novel theorizing on digital innovation management" which promises to become "a rich and potentially highly rewarding area of research for information systems researchers" (Nambisan et al. 2017). Another fruitful avenue of research concerns the interrelation between platform launch strategies and the enterprise architecture of the platform in general, and technology pivots in particular. Once a launch strategy turns out to be successful this often goes along not only with adaptations in the business architecture (e.g., price setting) but also in the application and infrastructure architecture. Hence, there is a need to adapt to this growth at some point in time with a so-called technology pivot (Ries 2011). Failing to pivot at the right time (and for the right reasons) can substantially jeopardize the success of a growing platform (Bohn and Kundisch 2018), even if the chosen launch strategy was the right one. Last but not least, a systematic exploitation of the increasing number of online posts discussing and also criticizing certain types of existing platforms (e.g., via Trustpilot) by means of text mining and sentiment analysis may provide useful insights regarding the improvement of already established platforms as well as regarding the usercentric design of new ones.
Acknowledgements We sincerely thank Wilhelm Klat for his contribution to an earlier version of this paper. This work was partially supported by the German Research Foundation (DFG) as part of the Collaborative Research Centre "On-The-Fly Computing" (SFB 901).

\section{References}

Ackerberg DA, Gowrisankaran G (2006) Quantifying equilibrium network externalities in the ACH banking industry. RAND J Econ 37(3):738-761

Anderson EG, Parker GG, Tan B (2014) Platform performance investment in the presence of network externalities. Inf Syst Res 25(1):152-172

Armstrong M (2006) Competition in two-sided markets. RAND J Econ 37(3):668-691

Armstrong M, Wright J (2007) Two-sided markets, competitive bottlenecks and exclusive contracts. Econ Theory 32(2):353-380

Bakos Y, Katsamakas E (2008) Design and ownership of two-sided networks: implications for internet platforms. J Manag Inf Syst 25(2):171-202

Bensinger G (2017) Airbnb valued at $\$ 31$ billion after new funding round. https://www.wsj.com/articles/airbnb-valued-at-31-bil lion-after-new-funding-round-1489086240. Accessed 29 Oct 2017

Binken J, Stremersch S (2009) The effect of superstar software on hardware sales in system markets. J Market 73(2):88-104

Bohn N, Kundisch D (2018) Much more than "same solution using a different technology": antecedents and consequences of technology pivots in software startups. In: Proceedings of the Multikonferenz Wirtschaftsinformatik, Lüneburg

Caillaud B, Jullien B (2003) Chicken \& egg: competition among intermediation service providers. RAND J Econ 34(2):309-328

Cennamo C, Santalo J (2013) Platform competition: strategic tradeoffs in platform markets. Strateg Manag J 34(11):1331-1350

Chao Y, Derdenger T (2013) Mixed bundling in two-sided markets in the presence of installed base effects. Manag Sci 59(8):1904-1926

Chu J, Manchanda P (2016) Quantifying cross and direct network effects in online consumer-to-consumer platforms. Market Sci 35(6):870-893

Clements MT, Ohashi H (2005) Indirect network effects and the product cycle: video games in the US, 1994-2002. J Ind Econ 53(4):515-542

CNBC (2017) Meet the 2017 CNBC Disruptor 50 companies. https:// www.cnbc.com/2017/05/16/the-2017-cnbc-disruptor-50-list-ofcompanies.html. Accessed 29 Oct 2017

Dou G, He P, Xu X (2016) One-side value-added service investment and pricing strategies for a two-sided platform. Int J Prod Res 54(13):3808-3821

Eisenmann TR, Parker G, Van Alstyne M (2006) Strategies for twosided markets. Harv Bus Rev 84(10):92-101

Eisenmann TR, Parker G, Van Alstyne M (2008) Opening platforms: how, when and why? Working Paper 09-030, Harvard Business School

Eisenmann TR, Parker G, Van Alstyne M (2011) Platform envelopment. Strateg Manag J 32(12):1270-1285

Evans DS (2003) Some empirical aspects of multi-sided platform industries. Rev Netw Econ 2(3):191-209

Evans A, Gawer PC (2016) The rise of the platform enterprise: a global survey. Center for Global Enterprise, New York

Fath G, Sarvary M (2003) Adoption dynamics in buyer-side exchanges. Quant Market Econ 1(3):305-335 
Gazé P, Vaubourg AG (2011) Electronic platforms and two-sided markets: a side-switching analysis. J High Technol Manag Res 22(2): $158-165$

Hagiu A (2009) Two-sided platforms: product variety and pricing structures. J Econ Manag Strateg 18(4):1011-1043

Hagiu A, Eisenmann T (2007) A staged solution to the Catch-22. Harv Bus Rev 85(11):25-26

Hagiu A, Rothman S (2016) Network effects aren’t enough. Harv Bus Rev 94(4):65-71

Hagiu A, Spulber D (2013) First-party content and coordination in two-sided markets. Manag Sci 59(4):933-949

Hagiu A, Wright J (2015) Multi-sided platforms. Int J Ind Organ 43:162-174

Katz ML, Shapiro C (1985) Network externalities, competition, and compatibility. Am Econ Rev 75(3):424-440

Kiesling E, Günther M, Stummer C, Wakolbinger LM (2012) Agentbased simulation of innovation diffusion: a review. Cent Eur J Oper Res 20(2):183-230

Kuek SC, Paradi-Guilford CM, Fayomi T, Imaizumi S, Ipeirotis P (2015) The global opportunity in online outsourcing. World Bank Group, Washington

Landsman V, Stremersch S (2011) Multihoming in two-sided markets: an empirical inquiry in the video game console industry. J Market 75(6):39-54

Liebowitz SJ, Margolis SE (1994) Network externalities: an uncommon tragedy. J Econ Perspect 8(2):133-150

Menezes N (2013) What is the story behind the creation of Amazon's Mechanical Turk? https://www.quora.com/What-is-the-storybehind-the-creation-of-Amazons-Mechanical-Turk. Accessed 23 Nov 2016

Muzellec L, Ronteau S, Lambkin M (2015) Two-sided internet platforms: a business model lifecycle perspective. Ind Market Manag 45:139-150

Nambisan S, Lyytinen K, Majchrzak A, Song M (2017) Digital innovation management: reinventing innovation management research in a digital world. MIS Q 41(1):223-238

Parker GG, Van Alstyne MW (2005) Two-sided network effects: a theory of information product design. Manag Sci 51(10):1494-1504

Parker GG, Van Alstyne MW, Choudrary SP (2016) Platform revolution: how networked markets are transforming the economy and how to make them work for you. Norton, New York

Porter ME (1980) Competitive strategy: techniques for analyzing industries and competitors. The Free Press, New York
Ries E (2011) The lean startup: how today's entrepreneurs use continuous innovation to create radically successful businesses. Crown Business, New York

Rochet JC, Tirole J (2003) Platform competition in two-sided markets. J Eur Econ Assoc 1(4):990-1029

Rochet JC, Tirole J (2004) Two-sided markets: an overview. Working paper, Institut d'Economie Industrielle, France

Rochet JC, Tirole J (2006) Two-sided markets: a progress report. RAND J Econ 37(3):645-667

Rysman M (2004) Competition between networks: a study of the market for yellow pages. Rev Econ Stud 71(2):483-512

Rysman M (2009) The economics of two-sided markets. J Econ Perspect 23(3): 125-143

Schilling M (2003) Winning the standards race: building installed base and the availability of complementary goods. Eur Manag J 17(3):265-274

Shankar V, Bayus BL (2003) Network effects and competition: an empirical analysis of the home video game industry. Strateg Manag J 24(4):375-384

Sokoler D (2011) How to solve the two-sided chicken-and-egg problem: a great harvest! http://www.onlineeconomy.org/tag/ lean-startup. Accessed 23 Nov 2016

Stremersch S, Tellis GJ, Franses PH, Jeroen LG (2007) Indirect network effects in new product growth. J Market 71(3):52-74

Tucker C, Zhang J (2010) Growing two-sided networks by advertising the user base: a field experiment. Market Sci 29(5):805-814

Veit D, Clemons E, Benlian A, Buxmann P, Hess T, Kundisch D, Leimeister JM, Loos P, Spann M (2014) Business models: an information systems research agenda. Bus Inf Syst Eng $6(1): 45-53$

Voigt S, Hinz O (2015) Network effects in two-sided markets: why a $50 / 50$ user split is not necessarily revenue optimal. Bus Res $8(1): 139-170$

Wilbur KC (2008) A two-sided, empirical model of television advertising and viewing markets. Market Sci 27(3):356-378

Wilson C, Boe B, Sala A, Puttaswamy K, Zhao BY (2009) User interactions in social networks and their implications. In: Proceedings of the 4th ACM European Conference, Nuremberg, pp 205-218

Yoo B, Choudhary V, Mukhopadhyay T (2002) A model of neutral B2B intermediaries. J Manag Inf Syst 19(3):43-68

Zhu F, Iansiti M (2012) Entry into platform-based markets. Strateg Manag J 33(1):88-106 